\title{
CARACTERÍSTICAS SENSORIAIS E ESTABILIDADE DE BEBIDA LÁCTEA SIMBIÓTICA COM SABOR GRAVIOLA
}

\author{
AMANDA DE MORAIS OLIVEIRA SIQUEIRA ${ }^{1 *}$ \\ ERILANE DE CASTRO LIMA MACHADO ${ }^{2 *}$ \\ THAMIRES DE SIQUEIRA CAMPOS $3^{3+* *}$ \\ LEONARDO PEREIRA DE SIQUEIRA ${ }^{4 *+* x}$ \\ THAYZA CHRISTINA MONTENEGRO STAMFORD ${ }^{5^{*+*+*+*}}$ \\ TÂNIA LÚCIA MONTENEGRO STAMFORD
}

\begin{abstract}
Produtos lácteos simbióticos são representantes em destaque entre os alimentos funcionais e por isso o mercado busca a aceitação de novas composições pelo consumidor. Assim, os objetivos desta pesquisa foram avaliar as características sensoriais e vida de prateleira da bebida simbiótica produzida com soro de queijo de coalho fermentado e polpa de graviola. As misturas $(n=10)$ foram definidas através de delineamento simplex aumentado. A análise sensorial foi dividida em teste de preferência e por análise descritiva quantitativa. A avaliação da vida de prateleira $(\mathrm{pH}$, acidez total titulável, coliformes, bolores e leveduras, estafilococos coagulase positiva e bactérias láticas totais) foi realizada após $0,7,14,21$ e 28 dias de produção da bebida. Os resultados mostraram que a bebida com $71,5 \%$ de soro apresentou boa aceitabilidade sensorial, e que $25 \%$ da polpa de graviola favoreceu a aceitação quanto ao sabor e aroma. A bebida manteve as características durante a vida de prateleira, principalmente as bactérias probióticas em níveis recomendados pela legislação vigente. Conclui-se que a aceitação sensorial e estabilidade no armazenamento viabiliza a produção da bebida simbiótica proposta, além de gerar alternativa para utilização do soro residual da produção de queijo de coalho, bem como possibilita redução das perdas pós-colheita da graviola.
\end{abstract}

PALAVRAS-CHAVE: ANNONA MURICATA L.; BEBIDA LÁCTEA; FRUTOOLIGOSSACARÍDEO; PROBIÓTICO; SORO DE QUEIJO DE COALHO.

*Doutora em Nutrição. Docente do Departamento de Tecnologia Rural, Universidade Federal Rural de Pernambuco (UFRPE). E-mail: amanda.morais@gmail.com

**Doutora em Nutrição. Docente do Centro Acadêmico de Vitória, Universidade Federal de Pernambuco. E-mail: erilane@ig.com.br

${ }^{* * *}$ Nutricionista formada pelo Centro Acadêmico de Vitória, Universidade Federal de Pernambuco. E-mail: thamiressiqueiracampos@gmail.com

****Doutor em Nutrição. Docente do Departamento de Tecnologia Rural, Universidade Federal Rural de Pernambuco (UFRPE). E-mail: Ip_siqueira@yahoo.com.br

*****Pós-Doutorado pela Universidade de Pernambuco. Docente do Departamento Medicina Tropical, Centro de Ciências da Saúde, Universidade Federal de Pernambuco. E-mail: thayzastamford@yahoo.com.br

******Doutora em Nutrição. Docente do Departamento de Nutrição, Centro de Ciências da Saúde, Universidade Federal de Pernambuco. E-mail: tImstamford@yahoo.com.br 


\section{INTRODUÇÃO}

A sofisticação crescente no mercado de alimentos busca atender demandas dos consumidores, não somente por alimentos convenientes e saudáveis mas também por alimentos que aportam uma diferenciação da composição clássica, por exemplo, as bebidas funcionais à base de soro de leite (BALDISSERA et al., 2011). No Brasil, a produção de bebida láctea é uma das principais opções de aproveitamento do soro de leite, sendo que as mais comercializadas são as bebidas fermentadas, visto que apresentam características sensoriais semelhantes ao iogurte (CALDEIRA et al., 2010). Além do Brasil, outros países têm consumido alimentos fermentados, principalmente os que apresentam micro-organismos probióticos, predominantemente dos gêneros Lactobacillus, Pediococcus e Bifidobacterium, representados por algumas espécies (ZARE et al., 2012).

Associadas aos micro-organismos probióticos, substâncias prebióticas como a inulina e os frutooligossacarídeos têm sido amplamente empregadas nas formulações de bebidas lácteas fermentadas, caracterizando o alimento como simbiótico. A adição dessas substâncias aos alimentos é justificada pelo fato de alguns micro-organismos probióticos - como as bifidobactérias fermentarem preferencialmente esses oligossacarídeos e outras fontes de carboidratos (KOMATSU et al., 2008).

Diante do exposto, o objetivo desta pesquisa foi desenvolver uma bebida fermentada a partir de soro lácteo e polpa de graviola com característica simbiótica, utilizando cultura probiótica e frutooligossacarídeo como ingrediente prebiótico, e avaliar as características sensoriais e vida de prateleira da bebida.

\section{MATERIAIS E MÉTODOS}

Soro de queijo de coalho tipo $\mathrm{A}$ foi coletado em recipientes estéreis diretamente do tanque de produção e acondicionados em caixas isotérmicas com gelo. As graviolas (Annona muricata L.) in natura, da variedade Crioula, obtidas em estágios de maturação "maduro", provenientes do Instituto Agronômico de Pernambuco foram lavadas em água corrente, sanitizadas em solução clorada a 100 ppm por 10 minutos e em seguida despolpadas, porcionadas em embalagens de $200 \mathrm{~g}$ e congeladas em freezer $\left(-20^{\circ} \mathrm{C}\right)$ até o momento de sua utilização.

As demais matérias-primas utilizadas foram o frutooligossacarídeo (FOS, Raftilose $\mathrm{P}^{\circledR}{ }^{\circledR}$, Orafti, Tienen, Bélgica, com grau de polimerização $2-7$; contendo $5 \%$ de glicose, frutose e sacarose), leite em pó desnatado e sacarose. Os micro-organismos empregados foram a bactéria lática Streptococcus salivarius subsp. thermophilus e os micro-organismos probióticos Lactobacillus acidophilus $\mathrm{LA}-5^{\circledR}$ e Bifidobacterium lactis $\mathrm{Bb}-12^{\circledR}$ (Bio RICH®-Hansen).

Para determinar as condições de fermentação do soro para produção da bebida e avaliação da interação dos micro-organismos com a substância prebiótica (FOS, Raftilose P95®), realizou-se uma cinética de desenvolvimento dos micro-organismos ( $S$. thermophilus, $L$. acidophilus LA-5, $B$. lactis $\mathrm{Bb}-12)$ com e sem frutooligossacarídeo cujo teor foi fixado em 5\% (SILVA et al., 2011). Antes da fermentação, procedeu-se o preparo do pré-inóculo com a cultura mista reativada mediante três repiques sucessivos em leite em pó desnatado reconstituído a $10 \%$, incubadas a $42^{\circ} \mathrm{C} / 6$ horas. Ao fim do período, o pré-inóculo foi mantido em temperatura de refrigeração $\left(4 \pm 1^{\circ} \mathrm{C}\right)$. A fermentação no soro de queijo de coalho tipo $A$ pasteurizado $\left(65^{\circ} \mathrm{C} / 30\right.$ minutos) foi conduzida a $42^{\circ} \mathrm{C} \pm 1^{\circ} \mathrm{C}$, durante 360 minutos em condições de aerobiose. A cada 30 minutos, alíquotas dos substratos foram submetidas à quantificação de micro-organismos a partir de análises em triplicatas e os resultados expressos como log UFC/mL (AOAC, 2002).

A enumeração de $S$. thermophilus foi realizada em ágar M17 contendo $5 \%$ de solução de lactose a $10 \%$ pela técnica de inoculação em profundidade e incubação a $37^{\circ} \mathrm{C}$ por 48 horas. 
Lactobacillus acidophilus LA-5 foram quantificados em ágar MRS pela técnica de inoculação em superfície e incubação a $42^{\circ} \mathrm{C}$ por 72 horas em anaerobiose. A contagem de $B$. lactis $\mathrm{Bb}-12$ foi realizada em meio de cultivo ágar MRS suplementado com $0,5 \mathrm{~mL}$ de solução de L-cisteína $\mathrm{HCL}$ a $10 \%, 1 \mathrm{~mL}$ de solução de cloreto de lítio a $10 \%$ e $0,02 \mathrm{~mL}$ de azul de anilina. A incubação se deu a $45^{\circ} \mathrm{C} / 72$ horas em condições de anaerobiose (AOAC, 2002).

A partir dos resultados da cinética foi realizada a fermentação do soro para a produção da bebida fermentada, ao qual foi adicionado leite em pó desnatado em diferentes concentrações (Tabela 1), $5 \%$ de frutooligossacarídeo (SILVA et al., 2011) e 10\% do inóculo com aproximadamente 9 log UFC/mL (determinado a partir da turbidez pela escala de McFarland), seguindo as etapas do fluxograma de processamento da bebida fermentada (Figura 1). A fermentação foi conduzida até atingir aproximadamente $0,6 \mathrm{~g}$ de ácido lático/100 g (BRASIL, 2000).
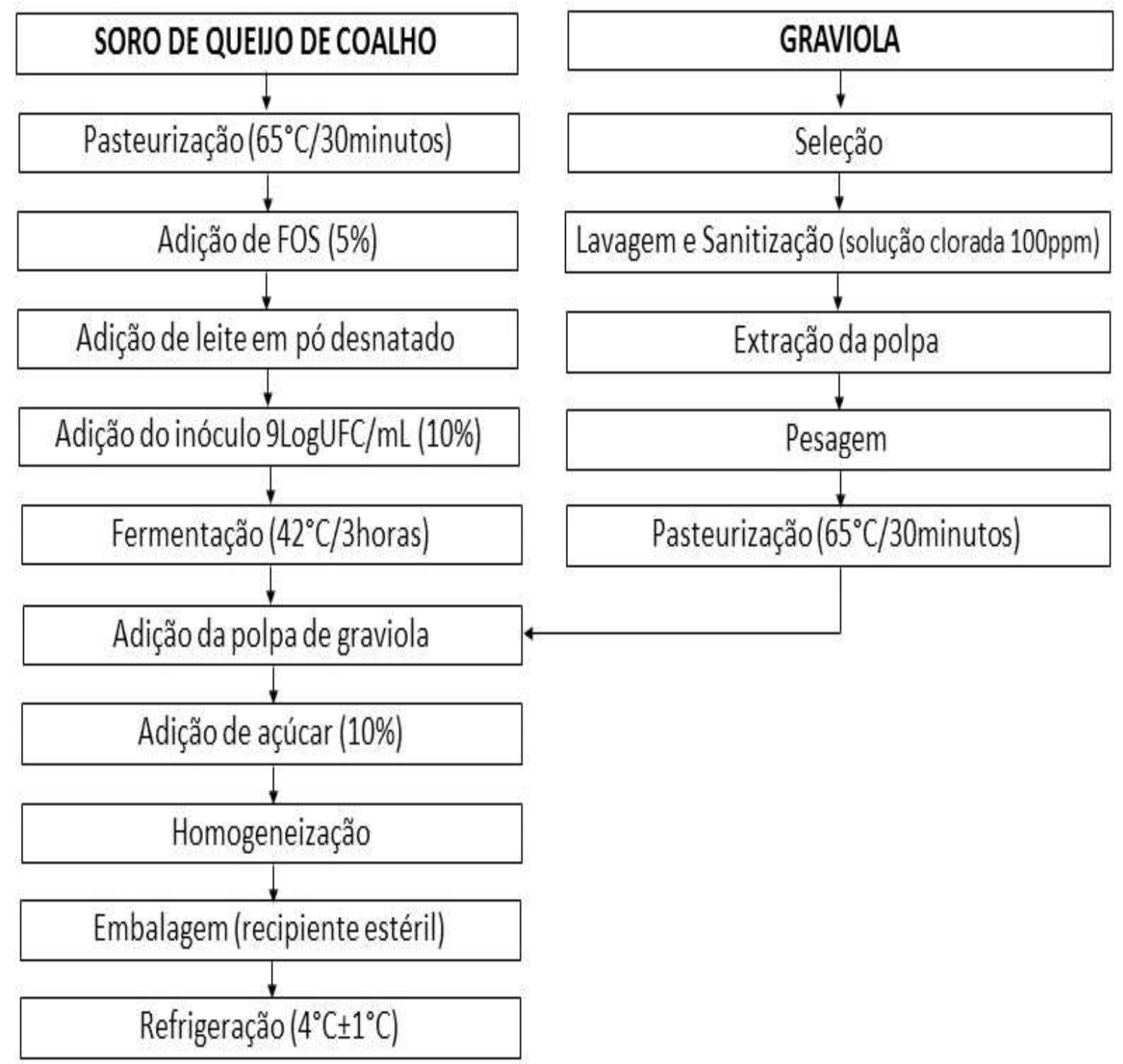

\section{FIGURA 1: FLUXOGRAMA DE PROCESSAMENTO DA BEBIDA FERMENTADA À BASE DE SORO DE LEITE E ADICIONADA DE POLPA DE GRAVIOLA.}

As proporções das misturas foram definidas empregando-se um delineamento simplex aumentado de misturas, definidas em dez tratamentos. Considerando que a soma das variáveis de uma mistura deve ser igual a $100 \%$, as restrições foram quanto ao mínimo de $66,5 \%$ de soro de queijo de coalho; $3,5 \%$ de leite em pó desnatado e $20 \%$ de polpa de graviola (Tabela 1 ). 


\section{TABELA 1: CONDIÇÕES EXPERIMENTAIS DO PLANEJAMENTO DE MISTURAS NA FORMULAÇÃO DA BEBIDA FERMENTADA À BASE DE SORO DE LEITE E DE POLPA DE GRAVIOLA.}

\begin{tabular}{cccc}
\hline $\begin{array}{c}\text { Formulaçóes } \\
\text { da bebida }\end{array}$ & $\begin{array}{c}\text { Leite em pó desnatado } \\
(\mathrm{g} / 100 \mathrm{~g})\end{array}$ & $\begin{array}{c}\text { Soro de queijo de coalho } \\
(\mathrm{g} / 100 \mathrm{~g})\end{array}$ & $\begin{array}{c}\text { Polpa de graviola } \\
(\mathrm{g} / 100 \mathrm{~g})\end{array}$ \\
\hline 01 & 13,5 & 66,5 & 20,0 \\
\hline 02 & 3,5 & 76,5 & 20,0 \\
\hline 03 & 3,5 & 66,5 & 30,0 \\
\hline 04 & 8,5 & 71,5 & 20,0 \\
\hline 05 & 8,5 & 66,5 & 25,0 \\
\hline 06 & 3,5 & 71,5 & 25,0 \\
\hline 07 & 6,8 & 69,8 & 23,3 \\
\hline 08 & 10,2 & 68,2 & 21,7 \\
\hline 09 & 5,2 & 73,2 & 21,7 \\
\hline 10 & 5,2 & 68,2 & 26,7 \\
\hline
\end{tabular}

Ao final da formulação das misturas, as bebidas foram homogeneizadas e adicionadas de açúcar (10\%). As bebidas foram envazadas em recipientes esterilizados e mantidas em temperatura de refrigeração $\left(4^{\circ} \mathrm{C} \pm 1^{\circ} \mathrm{C}\right)$ para avaliação das características sensoriais.

Os testes sensoriais foram realizados após 24 horas de elaboração das bebidas. As amostras foram codificadas utilizando sequência de três números aleatórios. As bebidas foram servidas em temperatura de refrigeração $\left(4^{\circ} \mathrm{C}\right.$ a $\left.8^{\circ} \mathrm{C}\right)$ em copos descartáveis de $50 \mathrm{~mL}$ sendo oferecidas água e bolacha de água no intervalo das amostras. Todos os testes sensoriais foram realizados em cabines individuais com controle de iluminação e de temperatura $\left(25^{\circ} \mathrm{C} \pm 1^{\circ} \mathrm{C}\right)$, respeitando-se o intervalo de duas horas antes ou depois das refeições. Antes de cada teste, os participantes assinaram o termo de consentimento livre e esclarecido conforme o previsto no projeto de pesquisa aprovada pelo Comitê de Ética e Pesquisa da Universidade Federal de

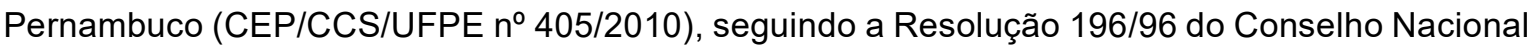
de Saúde.

Primeiramente, realizou-se um teste de preferência, com 75 provadores não treinados de ambos os sexos e idade entre 16 e 35 anos. As dez formulações foram avaliadas em dois blocos através de teste de ordenação para avaliação de preferência em relação à impressão global. Foi utilizada uma escala de 5 pontos para análise de preferência, onde a representação 1 correspondia a "menos preferida" e a 5 a "mais preferida".

Para avaliação da aceitação sensorial das formulações baseou-se na análise descritiva quantitativa (STONE; SIDEL, 2004), utilizando cinco formulações com as melhores médias obtidas no teste anterior. Para seleção de provadores foram recrutados 15 voluntários. Após avaliação do poder discriminativo de cada voluntário, através da aplicação do teste de sensibilidade aos gostos básicos (Threshold) foram selecionados 9 provadores que acertaram no mínimo $50 \%$ da avaliação (Morales, 1994). 
A partir da seleção de provadores, foi realizada a definição da terminologia descritiva a partir da apresentação das amostras aos provadores, os quais descreveram as similaridades e diferenças observadas quanto ao aroma, sabor, consistência e aparência. Partindo da lista de termos, os provadores discutiram o significado de cada termo, elaborando-se a ficha de avaliação sensorial contendo a definição de cada termo descritivo (Tabela 2).

\section{TABELA 2: DEFINIÇÕES DOS TERMOS DESCRITIVOS PARA AS AMOSTRAS DE BEBIDA LÁCTEA FERMENTADA COM POLPA DE GRAVIOLA.}

\begin{tabular}{lcl}
\hline \multicolumn{1}{c}{ DESCRITORES } & SIGLAS & \multicolumn{1}{c}{ DESCRIÇÃo } \\
\hline Frutal de graviola & AFG & Característico de graviola madura in natura \\
\hline Lácteo & AL & Sensação olfativa relacionada ao leite in natura \\
\hline Bebida láctea fermentada & ABLF & Associado ao aroma da coalhada \\
\hline Frutal de graviola & SABOR \\
\hline Lácteo & SL & $\begin{array}{l}\text { Sensação gustativa característica de graviola madura } \\
\text { in natura }\end{array}$ \\
\hline Sonsação percebida ao degustar leite e/ou derivados \\
\hline lácteos
\end{tabular}

Aavaliação foi realizada apresentando as amostras monadicamente (STONE; SIDEL, 2004). As amostras "mais preferidas" foram submetidas posteriormente ao teste sensorial de aceitação para avaliar os descritores relacionados à aparência, consistência, aroma e sabor, utilizando a escala hedônica de 9 pontos, cujos limites seguem a classificação: 1 para "desgostei extremamente" e 9 para "gostei extremamente". Na mesma ficha da análise de aceitação foi utilizada uma escala de 5 pontos para análise de intenção de compra (MEILGAARD et al., 1999), onde a representação 1 correspondia a "certamente não compraria" e a 5 a "certamente compraria".

Para o cálculo do índice de aceitabilidade do produto foi adotada a expressão (STONE; SIDEL, 2004): IA $(\%)=A \times 100 / B$, onde $A=$ nota média obtida para o produto e $B=$ nota máxima dada ao produto. 
Para a avaliação da vida de prateleira, a bebida elaborada foi avaliada após $0,7,14,21$ e 28 dias de sua produção, quanto ao $\mathrm{pH}$, acidez total titulável, análises de qualidade microbiológica (coliformes totais, coliformes termotolerantes, bolores e leveduras, estafilococos coagulase positiva) e de viabilidade celular dos micro-organismos probióticos (contagem de bactérias láticas totais), seguindo as preconizações da Association of Official Analytical Chemists (AOAC, 2002).

Os dados obtidos foram tratados estatisticamente por meio de análise de variância (ANOVA) e teste de Kruskall-Wallis, adotando-se nível de significância de $5 \%$ de probabilidade. Foi utilizado Bioestat $\circledast 5.0$.

\section{RESULTADOS E DISCUSSÃO}

Visando à observação da diferença do desenvolvimento microbiano padrão no soro de queijo de coalho, foi realizada a fermentação sem frutooligossacarídeo para avaliação comparativa da cinética de crescimento microbiano. Na Figura 2 observa-se que no sistema sem frutooligossacarídeo as bactérias Streptococcus thermophilus, Lactobacillus acidophilus e Bifidobacterium lactis apresentaram desenvolvimento adequado, contudo observa-se que a fase estacionária é curta e a fase de declínio se dá a partir da quarta hora de fermentação - provavelmente devido à exaustão dos nutrientes do soro de queijo, dos compostos de reserva no interior da célula e ao acúmulo de metabólitos microbianos.

A fermentação em soro de queijo de coalho com frutooligossacarídeo mostrou que a adição desse prebiótico prolonga o início da fase estacionária, não se observando a fase de declínio até a sexta hora de fermentação. Observa-se que as bactérias apresentaram simbiose, com desenvolvimento e manutenção das contagens superior ao sistema sem frutooligossacarídeo, caracterizado pelo acréscimo de um ciclo logarítmico, fator que favorece o processo tecnológico de produtos simbióticos (Figura 2B).

(A)

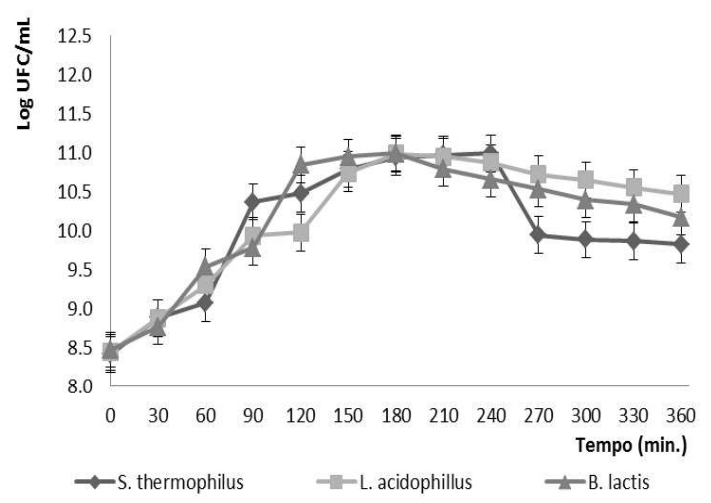

(B)

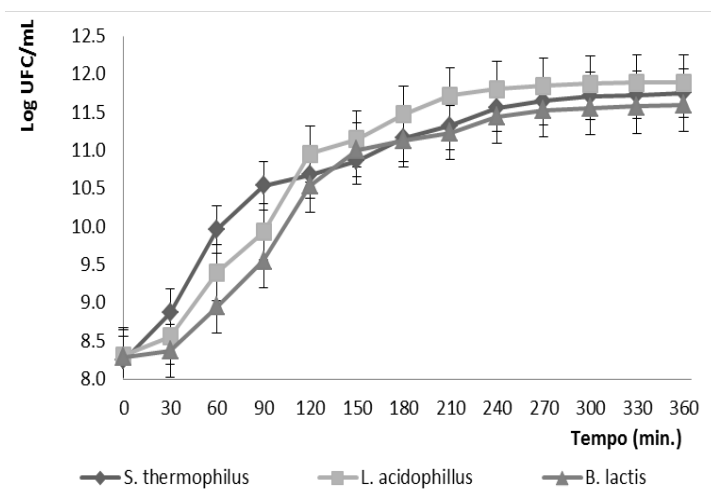

FIGURA 2: CINÉTICA DE DESENVOLVIMENTO DA CULTURA MISTA DA BACTÉRIA LÁTICA Streptococcus thermophilus E AS BACTÉRIAS PROBIÓTICAS Lactobacillus acidophilus e Bifidobacterium lactis EM SORO DE QUEIJO DE COALHO SEM FRUTOOLIGOSSACARÍDEO (A) E COM FRUTOOLIGOSSACARÍDEO (B) FERMENTADO A $42^{\circ} \mathrm{C}$ EM REPOUSO.

A Figura 2 confirma a característica simbiótica da mistura de soro de queijo de coalho e frutooligossacarídeo submetido à fermentação por micro-organismos probióticos como base para produção de uma bebida láctea. Cabe ressaltar que o desenvolvimento de uma bebida láctea simbiótica é estimulado pelo interesse dos consumidores em maximizar a saúde através 
da alimentação, o qual tem impulsionado a indústria de alimentos ao desenvolvimento de novos alimentos funcionais.

Baldissera et al. (2011) enfatizam que a aceitação do consumidor é um pré-requisito para que bebidas protéicas a base de soro tenham representação no preexistente mercado de bebidas lácteas. O desenvolvimento de bebidas com soro de leite pode ter as propriedades sensoriais otimizadas quando são submetidas ao processo de fermentação. De acordo com Jeličić et al. (2008), a fermentação do soro de leite utilizando cultura de iogurte produz um sabor de iogurte mais intenso em comparação com o obtido quando é utilizado o leite desnatado fermentado.

As amostras 2, 4, 6, 7 e 9 (formuladas com 76,5\%, 71,5\%, 71,5\%, 69,8\% e $73,2 \%$ de soro, respectivamente) obtiveram as melhores médias no teste de ordenação por preferência (Tabela 3). Na análise sensorial, as maiores médias foram obtidas pelas bebidas 4 e 6 , permitindo-se verificar que as amostras não diferiram significativamente entre si quanto aos atributos aroma, sabor, consistência e aparência, seguidas das amostras 2, 7 e 9, que também não apresentaram diferenças significativas $(p<0,05)$. Assim, as amostras "mais preferidas" foram submetidas à análise sensorial de aceitação para identificação da formulação com melhor característica sensorial.

\section{TABELA 3: RESULTADOS DO TESTE DE ORDENAÇÃO DAS AMOSTRAS DE BEBIDA LÁCTEA FERMENTADA COM POLPA DE GRAVIOLA.}

\begin{tabular}{ccccc}
\hline Bebida & Aroma & Sabor & Consistência & Aparência \\
\hline 1 & $5,23 \pm 1,47^{\mathrm{f}}$ & $5,05 \pm 1,34^{\mathrm{g}}$ & $5,13 \pm 1,41^{\mathrm{g}}$ & $5,19 \pm 1,34^{\mathrm{f}}$ \\
\hline 2 & $7,07 \pm 1,47^{\mathrm{c}}$ & $7,07 \pm 1,58^{\mathrm{c}}$ & $7,11 \pm 1,52^{\mathrm{c}}$ & $7,33 \pm 1,31^{\mathrm{bc}}$ \\
\hline 3 & $5,88 \pm 1,62^{\mathrm{e}}$ & $5,72 \pm 1,50^{\mathrm{ef}}$ & $6,00 \pm 1,63^{\mathrm{ef}}$ & $5,88 \pm 1,61^{\mathrm{e}}$ \\
\hline 4 & $7,83 \pm 0,72^{\mathrm{a}}$ & $7,81 \pm 0,82^{\mathrm{a}}$ & $7,80 \pm 0,77^{\mathrm{a}}$ & $7,84 \pm 1,01^{\mathrm{a}}$ \\
\hline 5 & $6,44 \pm 1,51^{\mathrm{d}}$ & $6,57 \pm 1,53^{\mathrm{d}}$ & $6,45 \pm 1,79^{\mathrm{de}}$ & $6,53 \pm 1,91^{\mathrm{d}}$ \\
\hline 7 & $7,61 \pm 0,91^{\mathrm{ab}}$ & $7,56 \pm 1,00^{\mathrm{ab}}$ & $7,60 \pm 0,98^{\mathrm{ab}}$ & $7,57 \pm 1,14^{\mathrm{ab}}$ \\
\hline 8 & $6,93 \pm 1,39^{\mathrm{c}}$ & $6,92 \pm 1,71^{\mathrm{cd}}$ & $6,91 \pm 1,44^{\mathrm{cd}}$ & $6,89 \pm 1,21^{\mathrm{cd}}$ \\
\hline 9 & $5,43 \pm 1,46^{\mathrm{f}}$ & $5,49 \pm 1,26^{\mathrm{fg}}$ & $5,56 \pm 1,48^{\mathrm{fg}}$ & $5,41 \pm 1,33^{\mathrm{f}}$ \\
\hline 10 & $7,25 \pm 1,01^{\mathrm{bc}}$ & $7,13 \pm 1,11^{\mathrm{bc}}$ & $7,15 \pm 0,91^{\mathrm{bc}}$ & $7,19 \pm 0,94^{\mathrm{bc}}$ \\
\hline $6,20 \pm 1,50^{\mathrm{de}}$ & $6,09 \pm 1,68^{\mathrm{e}}$ & $6,15 \pm 1,80^{\mathrm{e}}$ & $5,93 \pm 1,47^{\mathrm{e}}$ \\
\hline
\end{tabular}

Nota: Médias na vertical seguidas de letras iguais não diferem significativamente ao nível de $5 \%$ de significância pelo teste de Kruskal-Wallis.

Os resultados da análise descritiva quantitativa estão apresentados na Figura 3, a qual é representada ao centro com o ponto zero, e a cada eixo correspondente aos atributos avaliados é apresentada uma média, que conectadas entre si traçam o perfil sensorial das bebidas. 


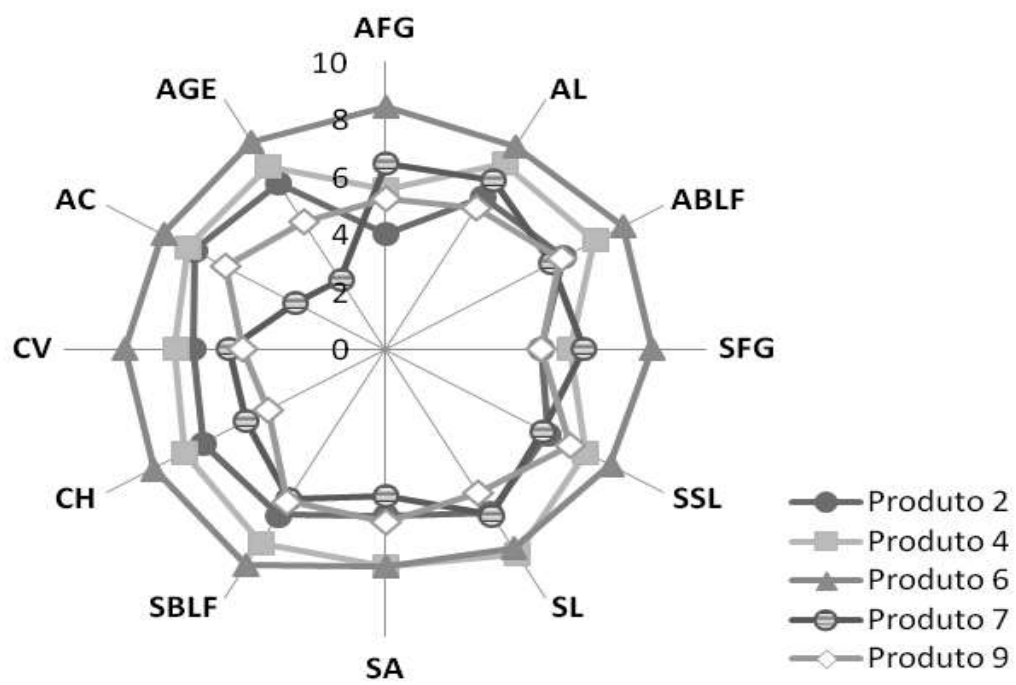

\section{FIGURA 3: PERFIL SENSORIAL DAS AMOSTRAS DAS BEBIDAS FERMENTADAS À BASE DE SORO LÁCTEO E POLPA DE GRAVIOLA.}

Nota: $\mathrm{AFG}=$ aroma frutal de graviola; $\mathrm{AL}=$ aroma lácteo; $\mathrm{ABLF}=$ aroma bebida láctea fermentada; $\mathrm{SFG}=$ sabor frutal de graviola; $\mathrm{SL}=$ sabor lácteo; $\mathrm{SSL}=$ sabor soro lácteo; $\mathrm{SA}=$ sabor ácido; $\mathrm{SBLF}=$ sabor bebida láctea fermentada; $\mathrm{CH}=\mathrm{con}-$ sistência homogeneidade; $\mathrm{CV}$ = consistência viscosidade; $\mathrm{AC}$ = aparência cor; $\mathrm{AGE}$ = aparência geral.

Observou-se que a formulação 6 da bebida fermentada à base de soro de leite e de polpa de graviola distinguiu-se das demais $(p<0,05)$ quanto aos atributos AFG e SFG, uma vez que dentre as formulações avaliadas apresentava o maior percentual de polpa de graviola. A bebida 6 também apresentou diferença significativa de cerca de $5 \%$ das outras amostras quanto ao atributo viscosidade (CV). Apesar da bebida 6 ter apresentado as maiores médias na avaliação dos provadores na maioria dos atributos, pode-se observar que não diferiu estatisticamente $(p<0,05)$ da bebida 4 quanto aos atributos de aroma AL e ABLF, atributos de sabor SL, SSL, SA e SBLF, bem como quanto à homogeneidade, viscosidade, cor e aparência geral (Figura 3).

Esses resultados são considerados satisfatórios, visto que as bebidas 4 e 6 apresentam a segunda maior concentração de soro de queijo de coalho $(71,5 \%)$ das formulações previstas no planejamento de misturas. No entanto, considerando que a bebida 6 apresentou as maiores médias quanto ao aroma e sabor de graviola e que diferiu significativamente $(p<0,05)$ das demais bebidas, ela pode ser considerada uma boa opção para produção, uma vez que apresenta a menor concentração de leite em pó desnatado, o que viabiliza economicamente o processamento.

Os resultados desta pesquisa dão embasamento para o favorecimento do consumo mais abrangente do soro lácteo, bem como gera mais uma aplicabilidade à graviola, fruto de alta perecibilidade e de curto período de conservação após a colheita, mas que possui características relevantes quanto à composição em açúcares, ácidos orgânicos e compostos fenólicos da polpa (LIMA et al., 2010).

Lutchmedial et al. (2004) avaliaram atributos sensoriais de aparência e cor, corpo e sabor, textura e aroma, e qualidade geral em iogurtes incorporados de néctar graviola $(0 \%, 5 \%, 10 \%$ e $15 \%)$. Os resultados revelaram que os iogurtes com $10 \%$ e $15 \%$ de néctar de graviola tiveram o maior índice de qualidade global $(p<0,05)$, mas diferiram em sabor e aroma de iogurte natural em relação ao iogurte com $5 \%$ de néctar de graviola $(p<0,05)$. De acordo com os autores, a maioria dos provadores considerou a intenção de compra para os iogurtes com 10\% e 15\% de néctar de graviola. Podendo-se inferir, portanto, que a maior concentração do fruto leva a uma maior aceitabilidade do produto e consequentemente a um iogurte com melhores atribuições nutricionais.

O desenvolvimento de um produto novo requer a avaliação de sua aceitabilidade com o objetivo de prever o seu comportamento diante do mercado consumidor. Assim, ao analisar o índice de aceitabilidade das bebidas (Tabela 4) foi possível verificar que apenas os atributos "consistência" da bebida 9 e "aparência" da bebida 7 foram inferiores a $70 \%$, índice mínimo para que o produto seja considerado como aceito sensorialmente (STONE; SIDEL, 2004). Observou-se também que as médias das notas atribuídas para a bebida 6 foram as maiores entre as bebidas avaliadas, bem 
como apresentou a maior média quanto à intenção de compra $(4,03 \pm 0,96)$, seguido da bebida 4 $(3,85 \pm 1,06)$, bebida $9(3,58 \pm 1,02)$, bebida $2(3,46 \pm 1,07)$ e da bebida $7(3,41 \pm 0,89)$.

\section{TABELA 4: ÍNDICES DE ACEITABILIDADE (\%) PARA AS AMOSTRAS DE BEBIDA LÁCTEA FERMENTADA COM POLPA DE GRAVIOLA.}

\begin{tabular}{cllll}
\hline \multirow{2}{*}{ Bebida } & \multicolumn{4}{c}{ Índice de aceitabilidade (\%) } \\
\cline { 2 - 5 } & Aroma & Sabor & Consistência & Aparência \\
\hline 2 & $86,46^{\mathrm{a}}$ & $85,45^{\mathrm{ac}}$ & $89,68^{\mathrm{ab}}$ & $90,67^{\mathrm{ab}}$ \\
\hline 4 & $89,87^{\mathrm{ac}}$ & $89,07^{\mathrm{ad}}$ & $86,95^{\mathrm{ac}}$ & $85,19^{\mathrm{ab}}$ \\
\hline 6 & $93,00^{\mathrm{bc}}$ & $92,47^{\mathrm{bde}}$ & $91,36^{\mathrm{bc}}$ & $90,74^{\mathrm{a}}$ \\
\hline 7 & $91,53^{\mathrm{ac}}$ & $84,81^{\mathrm{c}}$ & $82,41^{\mathrm{a}}$ & $66,94^{\mathrm{b}}$ \\
\hline 9 & $86,16^{\mathrm{a}}$ & $86,46^{\mathrm{aec}}$ & $66,93^{\mathrm{a}}$ & $83,86^{\mathrm{ab}}$ \\
\hline
\end{tabular}

Considerando que o maior escore de aceitação foi identificado na formulação da bebida 6 , ela foi submetida à avaliação da vida de prateleira. Evidenciou-se que houve decréscimo dos valores de $\mathrm{pH}$ e aumento da acidez no decorrer dos 28 dias de armazenamento, com importante gradiente de acidificação entre $\circ 21^{\circ}$ e $\circ 28^{\circ}$ dia (Tabela 5). Vale ressaltar que $\circ \mathrm{pH}$ final da bebida láctea fermentada com polpa de graviola mostrou-se semelhante à elaborada por Matos (2009), que sugere que a diminuição do pH e o aumento da acidez são decorrentes do fenômeno de pós-acidificação.

O processo de pós-acidificação das bebidas lácteas fermentadas ocorre pela combinação da cultura starter com as bactérias probióticas, as quais se mantêm ativas nas temperaturas de refrigeração e conseguem produzir pequenas quantidades de ácido lático por fermentação da lactose, resultando em perceptível diminuição do $\mathrm{pH}$. Mas algumas cepas probióticas mostram sensibilidade à acidez, e esse problema é agravado pela pós-acidificação no armazenamento, promovido pela $\beta$-galactosidase que ainda permanece ativa de $0^{\circ} \mathrm{C}$ a $5^{\circ} \mathrm{C}$ (BALLUS et al., 2010; SOARES et al., 2011). De acordo com Rodrigues et al. (2011) a suplementação do produto com frutooligossacarídeo e inulina não exerce influência global no fenômeno de pós-acidificação.

\section{TABELA 5. RESULTADOS DAS ANÁLISES FÍSICO-QUÍMICA E MICROBIOLÓGICAS DURANTE 28 DIAS DE ARMAZENAMENTO $\left(4^{\circ} \mathrm{C}\right)$ DA BEBIDA FERMENTADA À BASE DE SORO LÁCTEO E POLPA DE GRAVIOLA.}

\begin{tabular}{lccccc}
\hline \multirow{2}{*}{ PARÂMETROS } & \multicolumn{4}{c}{ TEMPO DE ARMAZENAMENTO (DIAS) } \\
\cline { 2 - 5 } & $\mathbf{0}$ & $\mathbf{7}$ & $\mathbf{1 4}$ & $\mathbf{2 1}$ & $\mathbf{2 8}$ \\
\hline pH & $5,23 \pm 0,02$ & $5,03 \pm 0,03$ & $4,96 \pm 0,01$ & $4,85 \pm 0,01$ & $4,03 \pm 0,57$ \\
\hline $\begin{array}{l}\text { Acidez titulável } \\
\text { (\% em ácido lático) }\end{array}$ & $0,61 \pm 0,01$ & $0,83 \pm 0,02$ & $1,05 \pm 0,01$ & $1,08 \pm 0,01$ & $1,20 \pm 0,02$ \\
\hline $\begin{array}{l}\text { Bactérias láticas totais } \\
\text { (logUFC/mL) }\end{array}$ & $8,61 \pm 0,04$ & $8,57 \pm 0,03$ & $8,51 \pm 0,01$ & $7,29 \pm 0,03$ & $7,20 \pm 0,03$ \\
\hline $\begin{array}{l}\text { Coliformes totais } \\
\text { (NMP/mL) }\end{array}$ & $<3,0$ & $<3,0$ & $<3,0$ & $<3,0$ & $<3,0$ \\
\hline $\begin{array}{l}\text { Coliformes termotolerantes } \\
\text { (NMP/mL) }\end{array}$ & $<3,0$ & $<3,0$ & $<3,0$ & $<3,0$ & $<3,0$ \\
\hline $\begin{array}{l}\text { Bolores e Leveduras } \\
\text { (UFC/mL) }\end{array}$ & Ausência & Ausência & Ausência & Ausência & Ausência \\
\hline $\begin{array}{l}\text { Estafilococos coagulase positiva } \\
\text { (UFC/mL) }\end{array}$ & Ausência & Ausência & Ausência & Ausência & Ausência \\
\hline
\end{tabular}


Aqualidade higiênico-sanitária da bebida foi demonstrada pela ausência de micro-organismos indicadores de contaminação durante o período de vida de prateleira (Tabela 5). A viabilidade celular dos micro-organismos S. thermophillus, L. acidophilus LA-5, B. lactis Bb-12 (contagem de bactérias láticas totais) na bebida mostrou-se eficiente, apesar de ter havido um decréscimo na contagem destas bactérias em um ciclo logarítmico. Contudo, o número de micro-organismos viáveis mantevese dentro dos níveis estabelecidos na Instrução Normativa n 16, de 23 de agosto de 2005, a qual prevê a contagem total mínima de $10^{6} \mathrm{UFC} / \mathrm{g}$ no produto final durante todo o prazo de validade para bebidas láticas fermentadas (BRASIL, 2005).

Diante desses resultados é relevante enfatizar que além das análises físico-químicas e microbiológicas, a análise sensorial também resultou numa importante ferramenta de qualidade para a bebida desenvolvida, visto que no planejamento de mistura - metodologia importante para o desenvolvimento e otimização de produtos alimentícios - as características de qualidade de um alimento normalmente dependerão das proporções dos ingredientes individuais que estão presentes nas formulações.

Por isso, vale ressaltar as afirmações de Moreira et al. (2010) de que a indústria de alimentos esforça-se continuamente para oferecer produtos novos e inovadores com o objetivo de satisfazer as necessidades do consumidor. Mas é imprescindível destacar ainda que o reaproveitamento do soro lácteo originário da produção de queijo de coalho é uma alternativa para aumentar a competitividade dos lacticínios com o desenvolvimento de outros produtos, além de evitar os gastos adicionais do tratamento desse resíduo com alto poder poluente.

\title{
CONCLUSÕES
}

A formulação da bebida láctea que apresentou melhor aceitação possuia baixa concentração de leite em pó desnatado e alta concentração de soro de queijo de coalho.

A presença da polpa de graviola em maior proporção na formulação da bebida láctea favoreceu sua aceitação quanto ao sabor e aroma.

As contagens dos micro-organismos probióticos utilizados (Lactobacillus acidophilus e Bifidobacterium lactis) mantiveram-se em níveis recomendados pela legislação brasileira vigente.

A adição do frutooligossacarídeo (FOS, Raftilose P95®) produziu efeito prebiótico sobre a microbiota probiótica avaliada nesta pesquisa, caracterizando a bebida como simbiótica.

\section{SENSORY CHARACTERISTICS AND STABILITY OF SYMBIOTIC SOURSOP-FLAVORED DAIRY DRINK.}

\begin{abstract}
Dairy products are symbiotic representatives among functional foods, and the market find the acceptance for new compositions by the consumer. The objectives of this study were to evaluate the sensory characteristics and shelf life of symbiotic beverage produced with whey "coalho" fermented and soursop pulp. The mixtures $(n=10)$ were defined by design simplex increased. Sensory analysis were divided into preference test and quantitative descriptive analysis. The evaluation of shelf life $(\mathrm{pH}$, titratable acidity, coliforms, yeasts and molds, Staphylococcus coagulase positive and total lactic acid bacteria) was performed after $0,7,14,21$ and 28 days of the drinking production. The results showed that the drink with $71.5 \%$ of whey showed good sensory acceptance, and that $25 \%$ of soursop pulp favored the acceptance for flavor and aroma. The drink maintained the characteristics during shelf life, especially probiotic bacteria at levels recommended by current legislation. It follows
\end{abstract}


that the sensory acceptance and storage stability sensory enables the production of the proposed symbiotic beverage, and generate an alternative to the use of whey from "coalho" cheese production, as well as turn possible the reduction the losses post-harvest soursop.

KEYWORDS: ANNONA MURICATA L., MILK DRINK, FRUCTOOLIGOSACCHARIDES, PROBIOTIC, WHEY "COALHO" CHEESE.

\section{REFERÊNCIAS}

1 AOAC - Association of Official Analytical Chemists. Official methods of analysis of AOAC International. Gaithersburg: Association of Analytical Communities, 2002. 1115p.

2 BALDISSERA, A.C.; DELLA BETTA, F.; PENNA, A.L.B.; LINDNER, J.D.D. Alimentos funcionais: uma nova fronteira para o desenvolvimento de bebidas protéicas a base de soro de leite. Semina: Ciências Agrárias, v. 32, n. 4, p. 1497-1512, 2011.

3 BALLUS, C.A.; KLAJN, V.M.; CUNHA, M.F.; OLIVEIRA, M.L.; FIORENTINI, A.M. Aspectos científicos e tecnológicos do emprego de culturas probióticas na elaboração de produtos lácteos fermentados: revisão. Boletim do Centro de Pesquisa de Processamento de Alimentos, v. 28, n. 1, p. 85-96, 2010.

4 BRASIL. Ministério da Agricultura e do Abastecimento. Resolução $n^{\circ}$ 5, de 13 de novembro de 2000. Padrões de identidade e qualidade de leites fermentados. Diário Oficial da União, Brasília, 27 nov. 2000.

5 BRASIL. MINISTÉRIO DA AGRICULTURA, PECUÁRIA E ABASTECIMENTO. Instrução Normativa n 16, de 23 de agosto de 2005. Regulamento técnico de identidade e qualidade de bebida láctea. Diário Oficial da União, Brasília, 24 de ago. de 2005.

6 CALDEIRA, L.A; FERRÃO, S.P.B; FERNANDES, S.A.A; MAGNAVITA, A.P.A; SANTOS, T.D.R. Desenvolvimento de bebida láctea sabor morango utilizando diferentes níveis de iogurte e soro lácteo obtidos com leite de búfala. Ciência Rural, v. 40, n.10, p. 2193-2198, 2010.

7 JELIČIĆ, I.; BOŽANIĆ, R.; TRATNIK, L.Whey-based beverages- a new generation of diary products. Mljekarstvo, v. 58, n. 3, p.257-274, 2008.

8 KOMATSU, T.R.; BURITI, F.C.A.; SAAD, S.M.I. Inovação, persistência e criatividade superando barreiras no desenvolvimento de alimentos probióticos. Revista Brasileira de Ciências Farmacêuticas, v.44, p.329-347, 2008.

9 LIMA, M.A.C.; ALVES, R.E.; FILGUEIRAS, H.A.C. Comportamento respiratório e amaciamento de graviola (Annona muricata L.) Após tratamentos pós-colheita com cera e 1-metilciclopropeno. Ciência e agrotecnologia, v.34, n.1, p. 155-162, 2010.

10 LUTCHMEDIAL, M.; RAMLAL, R.; BADRIE, N.; CHANG-YEN, I. Nutritional and sensory quality of stirred soursop (Annona muricata L.) yoghurt. International Journal of Food Sciences and Nutrition, v. 55, n. 5, p. 407-414, 2004.

11 MATOS, R.A. Desenvolvimento e mapa de preferência externo de bebida láctea à base de soro e polpa de graviola (Annona muricata). 2009. 79f. Dissertação (Mestrado em Engenharia de processos de Alimentos) - Universidade Estadual do Sudoeste da Bahia, Itapetinga, 2009.

12 MEILGAARD, M.; CIVILLE, G.V.; CARR, B.T. Sensory evaluation techniques. Boca Raton: CRC, 1999. 390p.

13 MORALES, A.A. La evaluación sensorial de los alimentos en la teoria y la práctica. Zaragoza: Acribia. 1994. 198p.

14 MOREIRA, R.W.M. ; MADRONA, G.S. ; BRANGO, I.G. ; BERGAMASCO, R.; PEREIRA, N.C. Avaliação sensorial e reológica de uma bebida achocolatada elaborada a partir de extrato hidrossolúvel de soja e soro de queijo. Acta Scientiarum. Technology, v. 32, n. 4, p. 435-438, 2010.

15 RODRIGUES, D.; ROCHA-SANTOSA, T.A.P.; PEREIRA, C.I.; GOMES, A.M.; MALCATA, F.X.; FREITAS, A.C. The potential effect of FOS and inulin upon probiotic bacterium performance in curdled milk matrices. LWT - Food Science and Technology, v. 44, n. 1, p. 100-108, 2011.

16 SILVA, L.M.R., LIMA, A.S., MAIA, G.A.; FIGUEIREDO, R.W.; SOUSA, P.H.M.; LIMA, J.S.S. Desenvolvimento de néctares mistos à base de manga e cajá enriquecidos com frutooligossacarídeos ou inulina. Alimentos e Nutrição, v. 22, n. 1, p. 149-154, 2011.

17 SOARES, D.S.; FAI, A.E.C.; OLIVEIRA, A.M.; PIRES, E.M.F.; STAMFORD, T.L.M. Aproveitamento de soro de queijo para produção de iogurte probiótico. Arquivo Brasileiro de Medicina Veterinária e Zootecnia, v.63, n.4, p. 996-1002, 2011. 
STONE, H.; SIDEL, J. L. Sensory evaluation practices. New York: Academic Press. 2004. 408 p.

19 ZARE, F.; ORSAT, V; CHAMPAGNE, C.; SIMPSON, B.K.; BOYE, J.I. Microbial and Physical Properties of Probiotic Fermented Milk Supplemented with Lentil Flour. Journal of Food Research, v. 1, n. 1, p. 94-109, 2012.

\section{AGRADECIMENTOS}

Ao CNPq pelos recursos financeiros e à Fundação de Amparo à Ciência e Tecnologia do Estado de Pernambuco (FACEPE) pelas bolsas de doutorado e iniciação científica concedidas. 